\title{
FLC- -98000447
}

\section{The Picatinny Technology Transfer Innovation Center:}

\author{
A Business Incubator Concept Adapted to \\ Federal Laboratory Technology Transfer
}

Tim Wittig

Project Manager

Geo-Centers, Inc.

and

James Greenfield

Technology Manager

Armaments Research, Development and Engineering Center

Picatinny Arsenal, U.S. Army

DISTRIBUTION OF THIS DOCUAEST IS UNIIITE:
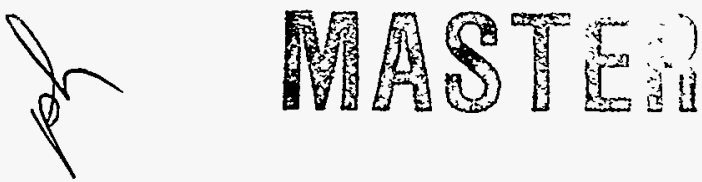

A project partially funded by the Federal Laboratory Consortium

Washington, DC

October 1996

Federal Laboratory Consortium Special Reports Series No. 7

ISSN 1075-9492C 
The production of this report was made possible by the cooperation and assistance of the FLC Northeast Region. We would also like to express our gratitude to Kathleen Hayes, Technology Transfer Information Center, USDA, National Agricultural Library, Beltsville, Maryland, who served as contributing editor. 


\section{DISCLAMIER}

Portions of this document may be illegible in electronic image products. Images are produced from the best available original document. 


\section{DISCLAIMER}

This report was prepared as an account of work sponsored by an agency of the United States Government. Neither the United States Government nor any agency thereof, nor any of their employees, make any warranty, express or implied, or assumes any legal liability or responsibility for the accuracy, completeness, or usefulness of any information, apparatus, product, or process disclosed, or represents that its use would not infringe privately owned rights. Reference herein to any specific commercial product, process, or service by trade name, trademark, manufacturer, or otherwise does not necessarily constitute or imply its endorsement, recommendation, or favoring by the United States Government or any agency thereof. The views and opinions of authors expressed herein do not necessarily state or reflect those of the United States Government or any agency thereof. 


\section{TABLE OF CONTENTS}

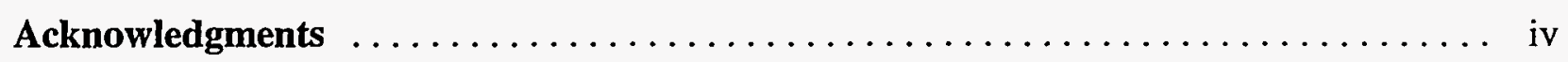

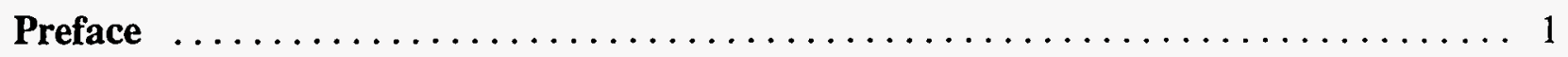

Technology Transfer at the Army Research, Development and

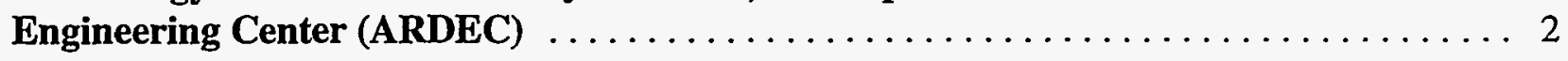

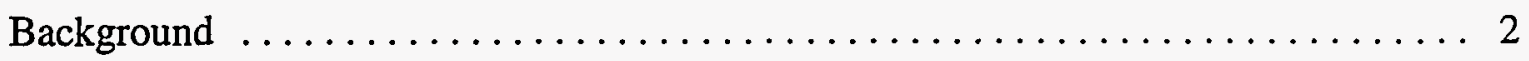

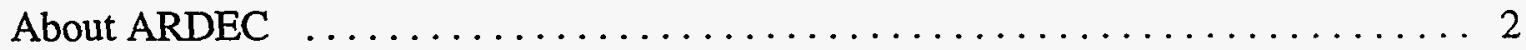

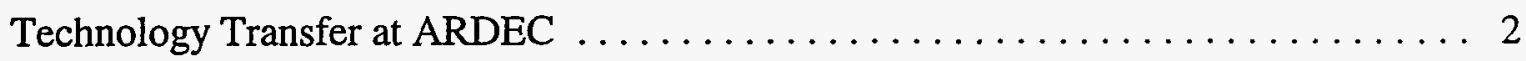

Adapting the Business Incubator Model

to Federal Technology Transfer at ARDEC $\ldots \ldots \ldots \ldots \ldots \ldots \ldots \ldots \ldots \ldots$

Facilities Use and Financial, Operational, and Management Training Assistance .... 5

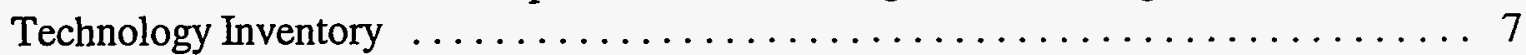

Potential Users and Criteria for Use $\ldots \ldots \ldots \ldots \ldots \ldots \ldots \ldots \ldots \ldots \ldots \ldots$

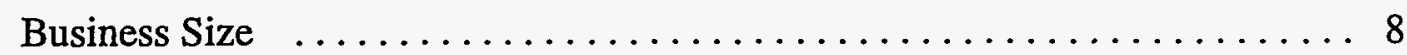

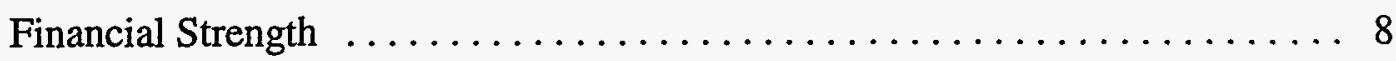

Intended Use of Technology $\ldots \ldots \ldots \ldots \ldots \ldots \ldots \ldots \ldots \ldots \ldots \ldots$

Origin of a Potential User $\ldots \ldots \ldots \ldots \ldots \ldots \ldots \ldots \ldots \ldots \ldots \ldots \ldots$

Term of Use by Potential Private Sector Organizations $\ldots \ldots \ldots \ldots \ldots \ldots$

Type of Intended Technology Transfer Project ................. 8

Cooperative Research and Development Agreement (CRADA)

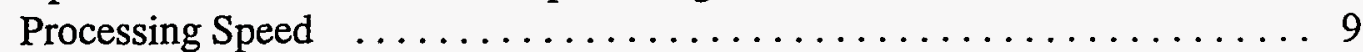

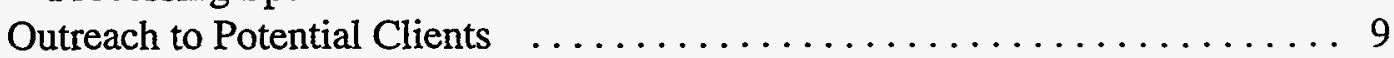

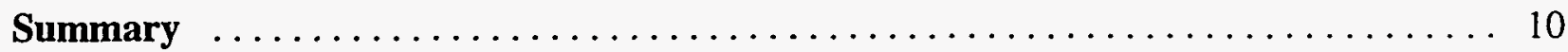

\section{Appendices}

A Excerpts from Chapter 63, U.S. Code, Regarding CRADAs $\ldots \ldots \ldots \ldots \ldots \ldots$. 11

B Tools for Creating a Business Incubator $\ldots \ldots \ldots \ldots \ldots \ldots \ldots \ldots \ldots \ldots \ldots \ldots \ldots \ldots \ldots$

C Statement of Work for ARDEC-Community College of Morris (CCM) CRADA $\quad \ldots \quad 13$ 


\section{ACKNOWLEDGMENTS}

The successful establishment of the Picatinny Technology Transfer Innovation Center at the Army Research, Development and Engineering Center (ARDEC), Picatinny Arsenal, NJ, was the result of 1.5 years of intensive effort by many key contributors. This project grew from an idea into reality under the leadership of Brigadier General J. W. Boddie, Jr., Commanding General of ARDEC; Ms. Renata Price, Associate Technical Director for Systems, Concepts and Technology; and Colonel Raymond Pawlicki, Chief, Advanced Systems Concepts Office.

We wish to express our sincere appreciation to the many individuals and groups who made this effort a success.

- The staff of Geo-Centers, Inc., our contractor for this effort, included Tim Wittig, Blake Sajonia, and Peter Blake. They answered a continuous stream of difficult questions regarding policy and practical application.

- The New Jersey Commission on Science and Technology provided key financial contributions.

- The Morris County Board of Chosen Freeholders (under the guidance of its Director, Sue Ostergaard) was the first public body to support the concept with encouragement and funds.

- Walter Kritch, Director of Planning for Morris County, deserves our special thanks for being the first public official to champion our effort.

- The Federal Laboratory Consortium (FLC) provided funding to support the study. Tina M. McKinley, Chair of the FLC; Dorry Tooker, Regional Coordinator of the FLC Northeast Region; and Gary Conlon, past Regional Coordinator of the FLC Northeast Region, all provided much needed encouragement.

- $\quad$ Several hundred gracious small- and medium-sized manufacturing business owners took the time to complete a questionnaire, which was created and administered by NFP Associates under the guidance of its president, Renee Slupski. The study gave us critical data about our target market and the attitudes of our potential clients.

- Dr. Edward Yaw, President of the County College of Morris, was our partner in the development of the Center from the beginning. Assisted by Herb Neal and Bruce Perkins, the College has assumed more and more responsibility for the operation of the Center and has helped to establish the links to the community that are critical to this effort.

- William Donnelly, President of the Morris County Chamber of Commerce, and Chris Marra, Director of the Morris Area Development Group, provided hours of advice as we developed this concept. 
- Gary Marx of the Jersey Central Power and Light Corporation provided support and artistic services for our logo.

- We also wish to thank the Advisory Board of Directors for their freely given advice-Philip Koos, John Carter, and others. 


\section{PREFACE}

The notion of technology transfer-the sharing of federal laboratory technology with the private sector-is widely accepted. It has been a matter of national interest since the mid-1980s. In recent decades, the federal government enacted legislation that not only encouraged but also required federal laboratories to actively pursue technology transfer. The Army Research, Development and Engineering Center (ARDEC), Picatinny Arsenal, NJ, is one of many federal organizations that fall under this legislative requirement to participate in technology transfer pursuant to its resources.

ARDEC's mission at Picatinny Arsenal is to provide the research, development, and engineering needed to arm the U.S. military with world-class armaments, including small and cannon caliber guns, artillery, and tank and helicopter armaments. Marketable resources and products in the technology transfer arena are limited due to ARDEC's mission, which focuses on weapons and related areas. In addition, ARDEC has a limited number of patents with commercial applicability. However, ARDEC's strength lies in its "can-do ability." It has numerous resources-including facilities, test equipment, and approximately 2,000 highly trained scientists and engineers.

By patenting and entering into Cooperative Research and Development Agreements (CRADAs), limited technology transfer can occur via commercialization and/or dual use of ARDEC products. However, with its "can-do-ability," ARDEC can be a valuable partner to state and local governments, academia, and private sector entities. In addition, ARDEC resources can be maximized by sharing the expertise of its scientists and engineers and its state-of-the-art facilities with the private sector.

With this background, ARDEC looked for an effective means to perform technology transfer. An internal review showed that the business incubator approach had promise because it permits resource sharing and partnering with state and local governments, academia, and the private sector. However, because of ARDEC's requirement that users sign a CRADA with ARDEC and various other limitations, ARDEC's incubator is not a full-fledged business incubator. Instead, it innovatively adapts the incubator concept to expand on CRADA partnerships.

This report highlights the issues identified, discussed, and resolved prior to the transformation of a temporarily vacant federal building on the Picatinny installation into a business incubator. ARDEC's discussions and rationale for the decisions and actions that led to the implementation of the Picatinny Technology Transfer Innovation Center are discussed. 


\section{TECHNOLOGY TRANSFER AT THE ARMY RESEARCH, DEVELOPMENT AND ENGINEERING CENTER}

\section{Background}

In recent years, the U.S. defense industrial base spawned the aerospace industry, among other successes, and served as the nation's technology seed bed. However, as the defense industrial base shrinks and public and private resources become scarcer, the merging of the commercial and defense communities becomes necessary to maintain our national technological competencies. Cooperative efforts such as technology transfer provide an attractive, cost-effective, wellleveraged alternative to independently funded research and development (R\&D). The sharing of knowledge, resources, and innovation among defense contractors and other public sector firms, academia, and other organizations has become exceedingly attractive. Recent legislation involving technology transfer provides for the sharing of federal laboratory resources with the private sector. The Army Research, Development and Engineering Center (ARDEC), Picatinny Arsenal, NJ, a designer of weapons systems, is one of the nation's major laboratories with this requirement.

To achieve its important technology transfer mission, ARDEC reviewed its capabilities, resources, intellectual property, and products with commercial potential. The purpose of the review was to develop a viable plan for effecting a technology transfer cultural change within the ARDEC, Picatinny Arsenal and with the private sector.

\section{About ARDEC}

Research, Development and Engineering Centers (RDECs) of the Army Materiel Command (AMC) are mission-focused organizations that concentrate on specific varieties of military hardware. RDECs generally do not develop a large body of commercially useful patented technology. However, they do tend to develop strong engineering capabilities in the areas of their respective mission assignments. These RDEC capabilities include know-how; expertise; and experience working with materials, manufacturing processes, design, and fault determination issues involving specific equipment.

ARDEC, Picatinny Arsenal, is the Army's principal source of energetic materials-ammunition and weapons. The Center is strong in the many manufacturing arts that are required to design and manufacture the guns, ammunition, propellants, and relative electronics (sensor packages) required for modern warfare. ARDEC is also responsible for the technology required to maintain weapons systems when they are in operation and to dispose of them at the end of their life cycle.

\section{Technology Transfer at ARDEC}

Most federal laboratories use several mechanisms for transferring technology. One mechanism is to license patents and patent applications to private sector firms. Another is to perform cooperative $R \& D$, in which laboratory and private sector teams work together to solve technological and industrial problems. Sometimes inventions result from these long-term research partnerships. 
ARDEC is different from most federal laboratories. Because of its mission, it has few patents and products of commercial interest to the private sector. In addition, $R \& D$ (specifically CRADAs) with the private sector usually adapt ARDEC's armaments technology to a manufacturing, design, materials, or performance problem. These technology transfer transactions usually involve sophisticated ARDEC equipment and technologies and take place mainly, if not completely, on the ARDEC site. (See Appendix A for legislation pertaining to CRADAs.)

Because ARDEC has few patents, there is no neatly defined package to which intellectual property ownership is readily attached-nor can such a package be readily understood, quantified, or evaluated by potential commercial users. This makes technology transfer much more difficult.

Another problem is that RDEC capabilities often appear to have little commercial value to private sector firms because they reflect a purely military product-such as an artillery shell or a weapon sighting system. Also, the unfamiliar names and distinctly military uses conceal from private sector manufacturers in different markets the engineering capabilities gained by designing, developing, and manufacturing such high technology military end items.

The Search and Destroy Armor (SADARM) smart projectile is a good example. SADARM contains the scientific and engineering skills and equipment necessary to create:

- an explosively formed penetrator useful for explosively forming instead of casting or forging a shaped charge design-which could be useful to the construction and mining industries

- a sensor system that can survive severe shock and spin environments-which is useful for process controls in unfriendly environments

- a complex targeting system that analyzes information from multiple sensors to select only appropriate targets-which could be useful in robotics manufacturing decision-making in harsh environments

- an environmental testing capability necessary to measure, in the laboratory, the performance of every part and the entire package under field conditions in order to identify failures and their causes in advance so that the package functions with extremely high reliability after many years of storage-which is useful for many manufacturers in product design and quality control.

Each of these engineering capabilities is hidden in the simple statement that ARDEC is responsible for developing the SADARM anti-tank artillery round. Only those private sector organizations intimately familiar with Army artillery manufacture would understand the capabilities inherent in the development of this artillery round. Unfortunately, existing military suppliers represent only a small portion of the audience to be addressed by technology transfer. Other private sector companies that could use these capabilities have no clue that the technology-as well as the experts who developed it-are available to them. 
It is apparent that ARDEC's technology transfer strengths lie in the areas of "can-do-ability"resources comprised of facilities, test equipment, and approximately 2,000 highly trained scientists and engineers. Such capabilities represent a tremendous resource for small- and mid-sized manufacturers that do not have their own research, development, and testing facilities but do have new products to develop or manufacturing problems to overcome.

With this "can-do-ability," ARDEC also can be a valuable partner to state and local governments and academia. The Center's resources can be maximized by sharing and partnering.

With the above background, extensive experience, and the knowledge that technology transfer works best when the parties work physically and closely together, the ARDEC staff investigated current technology transfer methods and the various tools and mechanisms available to effect successful technology transfer cultural change at ARDEC (see Appendix B).

Through these investigations and discussions and an analysis of previous experience, ARDEC concluded that:

(1) the transfer of know-how and expertise required a great deal more personal interaction between its scientists and engineers and commercial partners than the transfer of patented technology

(2) such transfers would require specific on-site machinery, equipment, and software developed by ARDEC to meet its mission requirements

(3) private sector organizations would use ARDEC technology in a way different from a more normal CRADA and patent licensing situation

(4) a successful technology transfer approach must include convenient ways for technology transfer clients to interact on-site with ARDEC scientists and engineers over a period of time without constantly interfering with the normal $R \& D$ operations at the facility

(5) military product-oriented technology had to be described in terms that could be understood by commercially-oriented businesses.

Based on some experience in the last area, ARDEC expected that most private sector organizations would bring either a specific product/process problem or a proposed new product to ARDEC and request manufacturing and/or material solutions based on the Center's design, process, materials, and inspection expertise. Thus, ARDEC's technology transfer endeavors were expected to be of long duration and to involve more ARDEC time and facilities than more direct CRADA- or patent-based efforts.

Based on these conclusions, it was obvious that ARDEC needed a nontraditional approach to technology transfer - one that would not burden the normal operation of ARDEC but would attract a steady stream of technology transfer clients seeking manufacturing and/or materials solutions to product/process problems based on the Center's design, process, materials, and inspection expertise. The staff agreed to study the feasibility of using the basic aspects of the 
business incubator to effect technology transfer at ARDEC. After meetings with the National Business Incubator Association (NBIA) and briefings with ARDEC management and the FLC representatives, ARDEC initiated the innovation center (incubator) study.

\section{ADAPTING THE BUSINESS INCUBATOR MODEL TO FEDERAL TECHNOLOGY TRANSFER AT ARDEC}

Surveys show that four out of five businesses fail in the first 5 years of operation, and a large number of studies identify the causes as management inexperience and under-capitalization. Management failures are the primary problem.

State and local governments throughout the nation use business incubators to help small and start-up businesses succeed. The incubator provides a sheltered environment for emerging businesses by providing low-cost, multiple use rental space; pooled secretarial and business services; office equipment; financial assistance; and management assistance classes (often required). This allows new businesses to overcome lack of business experience while reducing operating costs so that scarce assets can be used to grow the business. Some research into the success of this concept reveals that, when located in a business incubator environment, four out of five new businesses survive after 5 years of operation.

After reviewing the various available mechanisms, ARDEC staff decided that the essential elements of a business incubator-shared space, pooled services, and management assistance-provided through a Technology Transfer Innovation Center would help the organization in its technology transfer mission. The staff also determined that ARDEC was constrained by its mission and lack of funding and, therefore, could not create and operate such a Center by itself. After assessing the situation, ARDEC decided that:

- Department of Defense mission parameters permitted the use of a temporarily vacant building as well as desks, chairs, and other minor amenities for such an effort

- $\quad$ staff could not provide management training for business owners or supply funds for someone else to conduct the training

- $\quad$ salaries for the secretarial and managerial personnel necessary to operate a Technology Transfer Innovation Center (incubator) could not be provided.

\section{Facilities Use and Financial, Operational, and Management Training Assistance}

By statute, CRADAs permit the private sector to use an ARDEC building. However, ARDEC was concerned about dedicating too large a space to this effort, and the staff concluded that any building provided for a Technology Transfer Innovation Center should be used only for administrative purposes. Thus, a CRADA partner would assist in operating the Center, and additional CRADAs would provide private sector partners with access to specific laboratory space or equipment for a particular technology transfer effort. 
Thus, the use of the Center and any laboratory space and equipment would depend on a pre-existing CRADA between ARDEC and the private sector organization. ARDEC's environmental hazard control personnel were pleased with this decision because they believed that private sector clients might not be as sensitive to environmental regulations and might place the installation at risk. Senior management also supported this approach because it gave ARDEC absolute control over the entire effort.

Still concerned about its fiscal and mission constraints, ARDEC solicited non-government partners that could provide the necessary elements not available from ARDEC. These elements included:

- direct or indirect funding for facility operation

- $\quad$ secretarial assistance

- $\quad$ payment of building utility costs

- management training of many kinds, including federal, state, and local tax issues

- $\quad$ personnel management, accounting, finance (both debt and equity), marketing, inventory control, etc.

- marketing of the Technology Transfer Innovation Center.

After considering a number of potential partners that could provide some or all of the missing elements, ARDEC selected a community college, County College of Morris (CCM), that was located in the same county as the installation. ARDEC based this decision on: CCM's excellent reputation in the traditional and continuing educational markets, the strong support of the county government, and the capabilities of the college executive. ARDEC and CCM continued to assess their needs and subsequently began to search for the elements they could not provide-funding and management training.

They considered it essential to find funding to sustain the effort from its opening through the first 3 years. They created a business plan and pro-forma financials that estimated staffing, supplies, utilities costs, and similar operating expenses. Based on this evaluation of need, ARDEC raised $\$ 175,000$ from the FLC, the State of New Jersey, and the county government. ARDEC and $\mathrm{CCM}$ considered this amount sufficient enough to proceed with confidence before initiating fund raising requests to the local business community.

ARDEC subsequently created links with the State of New Jersey Small Business Development Center (SBDC), which sponsors and provides weekly management assistance training throughout the state. Through this organization, a broad range of management training and counseling services not otherwise available from CCM would be brought to Technology Transfer Innovation Center clients in need of such support.

At this point, ARDEC reviewed and resolved a number of real and perceived problems-including: the development of an inventory of ARDEC technology available for transfer; a description of acceptable Technology Transfer Innovation Center clients; the identification of outreach methods to clients; and increasing the speed with which CRADA approvals are consummated by ARDEC and the private sector partner. 


\section{Technology Inventory}

ARDEC initially determined that this effort would not succeed without a catalog of ARDEC's commercially valuable technology - an effort never before undertaken by the organization. ARDEC managers reasoned that it could not attract technology transfer partners without being able to describe the commercial value of its technology, expertise, and facilities. Merely declaring the ARDEC installation open for technology transfer was not sufficient. An initial listing of commercially applicable technology was prepared and used as a guide for this effort.

Discussions with the manager responsible for each technology area uncovered the capabilities and potential commercial uses of the expertise, equipment, and facilities maintained by ARDEC. Information concerning each technology area was then reduced to a plain language description not longer than two pages. Although more technical descriptions of the technologies and their accompanying equipment and facilities already existed, they were written in language most readily understood by individuals who were already familiar with that particular military technology and its military uses. In other words, military-oriented engineers wrote technical descriptions for other military-oriented engineers. Although this approach made for rapid communication between military users, it generally confused potential private sector companies. Therefore, without plain text descriptions, communication with the intended private sector manufacturers concerning the technical strength and the commercial value of ARDEC technology was destined to fail. It is important to note that although this effort is time-consuming, it cannot be avoided. If the most commercially valuable technology is not described in terms that others can understand, it will not be appreciated or used by the private sector.

\section{Potential Users and Criteria for Use}

Once the identification of available technology was underway, ARDEC turned to analyzing the potential users of its technology. Having determined that its patent portfolio was not its most valuable asset, the staff reviewed its collective know-how, expertise, equipment, and facilities to locate common themes and subsequently identified the manufacturing and allied industries sector as the business area most likely to be interested in its technology. ARDEC staff then began identifying the communication channels most appropriate for reaching this business sector.

During this analysis, the staff discussed the kinds of private sector organizations that would be eligible users of the Center and the acceptable intended uses of the Center. ARDEC had already stipulated that private sector access to the general facility and space, equipment, and expertise would exist through CRADAs. To some extent, this limited use of the Center. The staff recognized that further limitations regarding size, financial strength, intended use of technology, user origin, and term of use by clients would affect the viability of the Center even more; in other words, the pool of potential users would be too small to support a self-sustaining operation. On the other hand, staff believed that lenient criteria could cause the Center's operation to exceed ARDEC mission and authority-thereby forcing ARDEC to withdraw its support of the Center. The staff subsequently addressed and resolved the following issues. 
Business Size: Business size in terms of the number of employees is an important issue in technology transfer. Although the authorizing statutes do not restrict the size of any private sector technology transfer candidate, they do require that preference be given to "small businesses," as defined by the Small Business Act. ARDEC determined that the potential business size of Center users could range from individuals (e.g., retired ARDEC employees or university staff) to one to three person start-up operations to teams from large companies. The staff had no concerns in this area and even felt that by providing management assistance, low cost space utilization, and secretarial support, smaller businesses would be favored.

Financial Strength: The staff envisioned the Center as a self-sustaining operation. Thus, its use by organizations unable to pay even the low cost of occupancy would lead to failure. The staff recognized that a deficit operation would more deeply involve ARDEC and that a continual search for outside funding to sustain the operation was too great a risk. It was decided that private sector organizations interested in using the Center had to demonstrate sufficient capability to assume Center fees for at least 1 year.

Intended Use of Technology: The most important consideration here was the requirement that the private sector client must enter into a CRADA with ARDEC with the intent to use ARDEC technology for a commercial purpose that would tend to strengthen the U.S. economy. With this in mind, ARDEC determined that potential Center users be limited to those that intend, at least in part, to use ARDEC technology to create or improve a product, process, or service that would be sold to or used by parties not related to the U.S. government. With this restriction, ARDEC limited use of the Center to those private sector organizations whose technology utilization plan fit the statutory authority.

Origin of a Potential User: Because its mission of research, development, and engineering involves significant items of military hardware, the staff was concerned about the geographical (e.g., national) origin of a potential partner. The statute governing technology transfer usually provides the guidance relative to foreign companies, but the staff decided to review these issues on a case-by-case basis depending on the approval process of each CRADA between the private sector organization and ARDEC.

Term of Use by Potential Private Sector Organizations: This issue was intertwined with the issues in the following sections. Because ARDEC, as a participant in technology transfer, cannot compete with the private sector, ARDEC could not allow its facilities to be used as a permanent home by its private sector partners. If this were allowed, ARDEC would be competing with local private sector real-estate owners who provide business space. For this reason, ARDEC chose to limit use of the Center by private sector firms to 5 years-with an expectation that most businesses would leave the Center for space outside the installation after 3 years. ARDEC created this guideline to preclude the appearance of competing with tax paying landlords who provide rental space for commercial and industrial clients.

Type of Intended Technology Transfer Project: ARDEC also had to avoid the real and perceived appearance of competing with the local, private real estate market, which provides manufacturing space. Therefore, ARDEC could not agree to a proposed technology transfer 
project that involved establishing a permanent manufacturing line that created mass-produced projects. However, ARDEC could consider creating a pilot line using ARDEC facilities and expertise.

CRADA Processing Speed: The time needed for ARDEC to process a CRADA was extreme. Experience showed that unless this time was reduced significantly, small businesses would lose interest in the Center and technology transfer projects. Of equal importance, a long CRADA processing time tells potential partners that doing business with ARDEC is unlikely to yield useful solutions in a timely manner. Consequently, speed in CRADA processing was important.

After considering this problem at length, ARDEC took a number of steps to solve it. The staff identified the chain of command required for CRADA approval, developed a processing form, and used the form for several CRADAs to successfully test its appropriateness.

ARDEC also created a generic expandable CRADA. The previous normal length of a CRADA was 28 pages. The ARDEC basic CRADA is now 10 pages and can be expanded to 16 pages depending on the specific needs of the project. By using an expandable format, potential partners are not required to analyze clauses that are not applicable to their project. As a result, they are not as intimidated as they otherwise might be. This approach is expected to bring both speed and clarity to each project.

Outreach to Potential Clients: Manufacturing businesses of all types and sizes are expected to be interested in the Technology Transfer Innovation Center. A survey of businesses located in northern New Jersey, Eastern Pennsylvania, and adjacent sections of New York showed that, preliminarily, approximately 180 very small to small manufacturing businesses were interested in partnering with ARDEC in the Center. To reach these and other manufacturing businesses, ARDEC, in cooperation with its intended CRADA partner and other interested private sector entities, is developing a plan to use a number of newspaper and radio outlets for advertising the center. For the "grand" opening, these outlets include: state-wide newspapers; the New York Times; the Wall Street Journal; magazines; local newspapers; and direct mail. The direct mail notices will be sent to the 180 businesses previously identified and to the state Departments of Commerce manufacturing business listing and state and local Chambers of Commerce.

Continuing coverage of the Center's operation and successes will be sent to local and regional radio talk shows; local and regional business-oriented television channels; local community interest television channels; state-wide newspaper business sections; local newspapers; SBDC state-wide small business bulletin board; and large company internal bulletin boards and newsletters.

It is important to note that once the effort of announcing the opening of the Center begins, a large number of personnel will be needed to respond to the inquiries. Assistance will be needed to answer calls, send material, provide guided tours of the ARDEC facilities, discuss potential CRADA opportunities, write CRADAs, screen candidates, and approve CRADAs and Use of Facilities agreements. This is no small task and will require much more short-term but sustained effort than either the creation of the Center or its daily operation. Staff assisting with the initial 
endeavor must also be familiar with the CRADA process and the technology, equipment, facilities, and science and engineering expertise at ARDEC.

\section{SUMMARY}

This study involved researching, investigating, and establishing the foundations required for the creation and operation of a Technology Transfer Innovation Center (Incubator) at ARDEC, Picatinny Arsenal, NJ. The incubator concept was studied as a tool to improve the quantity and quality of technology transfer activity at ARDEC. The Technology Transfer Innovation Center was modeled after business incubators used by state and local governments to promote economic development. However, because of ARDEC's requirement that users sign a CRADA with ARDEC and various other limitations, ARDEC's incubator is not a full-fledged business incubator. Instead, it innovatively adapts the incubator concept to expand on CRADA partnerships. Investigating the operational and legal issues raised by the creation and operation of such a Center, drafting a proposed business plan, and drafting the proposed agreements between the CRADA partner responsible for the operation of the Center and ARDEC, between the Center and its potential clients, and between ARDEC and Center clients consumed much of this effort.

After almost a year of negotiations and discussions with potential partners and with the ARDEC command structure, ARDEC entered into a CRADA with CCM. The statement of work explaining the intent of the parties is included as Appendix $\mathrm{C}$.

This study concludes that it is possible to establish a Technology Transfer Innovation Center as an integral part of a federal laboratory.

This technology transfer approach has never before been used by a government-owned and government-operated laboratory. By carefully ascertaining prerequisite conditions, methodically approaching each requirement, and forming a broad-based partnership with state and local government economic development organizations and academia, ARDEC and its CRADA partner, CCM, saw the Technology Transfer Innovation Center become an operational reality in the summer of 1996. Readers of this report are encouraged to contact Mr. James Greenfield of the ARDEC Office of Research and Technology Applications at 201-724-6048 for additional details and the latest developments on this project. 


\section{APPENDIX A \\ EXCERPTS FROM CHAPTER 63, U.S. CODE, TITLE 15, COMMERCE AND TRADE ${ }^{1}$}

3710a. Cooperative research and development agreements

(a) General authority

Each Federal agency may permit the director of any of its Government-operated Federal laboratories, and, to the extent provided in an agency-approved joint work statement, the director of any of its Government-owned, contractor-operated laboratories--

(1) to enter into cooperative research and development agreements on behalf of such agency (subject to subsection (c) of this section) with other Federal agencies; units of State of local government; industrial organizations (including corporations, partnerships, and limited partnerships, and industrial development organizations); public and private foundations, nonprofit organizations (including universities); or other persons (including licensees of inventions owned by the Federal agency); and

(2) to negotiate licensing agreements under section 7 of title 35, United States Code, or under other authorities (in the case of a Government-owned, contractor-operated laboratory, subject to subsection (c) of this section) for inventions made or other intellectual property developed at the laboratory and other inventions or other intellectual property that may be voluntarily assigned to the Government.

(d) Definitions

As used in this section--

(1) the term "cooperative research and development agreement" means any agreement between one or more Federal laboratories and one or more non-Federal parties under which the Government, through its laboratories, provides personnel, services, facilities, equipment, intellectual property, or other resources with or without reimbursement (but not funds to non-Federal parties) and the non-Federal parties provide funds, personnel, services, facilities, equipment, intellectual property, or other resources with or without reimbursement (but not funds to non-Federal parties) and the non-Federal parties provide funds, personnel, services, facilities, equipment, intellectual property, or other resources toward the conduct of specified research or development efforts which are consistent with the missions of the laboratory; except that such terms does not include a procurement contract or cooperative agreement as those terms are used in sections 6303, 6304, and 6305 of Title 31 .

\footnotetext{
' Federal Laboratory Consortium. Technology Innovation. Special Report Series No. 1. Washington, DC: Federal Laboratory Consortium 1994.
} 


\section{APPENDIX B \\ TOOLS FOR CREATING A BUSINESS INCUBATOR}

- Cooperative Research and Development Agreements (CRADAs)

- $\quad$ Patent Licensing Agreements

- State/Local Government Assistance

- University/College Interaction

- Expert/Technical Assistance

- Technical Expos/Shows

- Unique Facilities

- Consortia

- Incubator

- Educational Partnerships

- $\quad$ Leveraging Small Business Innovative Research (SBIR) and Innovative Research and Development (IR\&D)

- Grants and Cooperative Agreements 


\section{APPENDIX C \\ STATEMENT OF WORK FOR ARDEC-CCM CRADA}

\section{PURPOSE}

This cooperative research and development effort is intended to develop, prototype, and test tools which will improve the quality and quantity of technology transfer at the Armaments Research, Development, and Engineering Center (ARDEC) and improve the likelihood that ARDEC cooperative technology transfer efforts will result in the fielding of new and improved products, processes and services which will strengthen the position of the U.S. economy in the work marketplace. This cooperative research and development effort will aid in the achievement of the ARDEC mission.

\section{BACKGROUND}

ARDEC, unlike Army laboratories which concentrate on basic and applied research, does not have a large portfolio of patented inventions that have direct commercial applications.

Rather, ARDEC has developed, in accordance with its mission, a great store of world class manufacturing expertise and know-how that, although very useful in the process of designing, testing, and manufacturing new or improved products, is generally not useful as a new product.

Unlike the transfer of patented technology to the private sector, manufacturing expertise is more difficult to describe and to market and each transfer action has, overall, a smaller payoff to the private sector partner. This makes the process of technology transfer more difficult for ARDEC than that of the basic and applied research laboratories and has retarded the quantity technology transfer actions successfully launched by ARDEC and its commercial partners.

The County College of Morris, a very highly regarded and successful academic institution has significant capability in the operation, scheduling, presentation, etc. of practical instruction programs in its continuing education division which serves thousands of students each year and has strong ties with the local economic community surrounding ARDEC where hundreds of small, medium and large businesses are located.

Working with the local community, ARDEC and the County College of Morris, will develop and test a Technology Transfer Innovation Center, A DoD unique approach to improve both the quality and the quantity of technology transfer actions which the parties believe, through cooperative effort, will benefit both the ARDEC mission, the County College of Morris, and private sector organizations.

Long experience among business development professionals has shown that technology transfer as well as commercial product development efforts are most effective when cooperating parties are closely co-located and not widely geographically separated so that frequent interaction is possible. Further, to the extent that start-up businesses and product development teams can conserve scarce cash resources for product development, marketing, and distribution, the more likely that the organization will succeed. Last, it is clear that 4 out of 5 small businesses fail in 
the first 5 years of operation due to failure of management whereas 4 out of 5 small businesses which are located in a business incubator environment succeed after 5 years of operation.

\section{$\underline{\text { Objective }}$}

This joint research, development and testing effort is intended to combine an administrative space within temporarily available buildings; ARDEC technology and available management assistance that will:

- $\quad$ reduce the cost of a technology transfer project

- $\quad$ improve the likelihood of success of that technology transfer project

- make technology transfer with ARDEC scientists more less complicated, and* make ARDEC a more attractive cooperative research and development partner

$\underline{\text { Goal }}$

ARDEC intends by this agreement to work cooperatively with CCM to establish, develop and test a Technology Innovation Center, operated by the CCM, using available buildings or parts thereof within the boundaries of Picatinny Arsenal.

\section{Approach}

The Technology Innovation Center will provide, primarily to small businesses but also to other organizations which have entered into a CRADA with ARDEC (ELIGIBLE ORGANIZATIONS) administrative space, pooled secretarial and administrative services, office equipment and shared conference room space and access to a wide variety of management and financial training and consulting services provided by Federal, State, and Local sources, at no cost to ARDEC. In addition, this Technology Innovation Center will be managed by an experienced director, employed by CCM, with direct experience in the establishment and finance of small businesses who will provide, as requested, continual advice and counsel concerning business operation and finance, assisting any ARDEC CRADA partner in preparing and presenting debt and equity proposals.

It is the intent of the parties that this Technology Innovation Center combine the beneficial efforts of close proximity of private sector partners to ARDEC scientists and engineers with the cost cutting, management strengthening, and financial assistance available in a business incubator environment. Through the development and use of this new tool, the parties intend to make ARDEC a more desirable cooperative research and development partner and to increase the likelihood that cooperative research and development efforts undertaken by ARDEC will in fact result in new or improved products, processes and services being offered to the public, new jobs being created, and the enhancement of the United States economy.

\section{ARDEC WILL:}

- $\quad$ Provide access to building \#3159 and other buildings within the Picatinny Arsenal to the CCM which are in good repair and suitable for Center use. 
- $\quad$ Provide assistance to the CCM in making the presence of such a Technology Innovation Center known to potential ARDEC CRADA partners.

- $\quad$ Provide services in support of the Technology Innovation Center as agreed.

- Designate an ARDEC representative to the Center advisory board, including the Associate Technical Director for Technology.

- $\quad$ Provide support, advice and coordination for the operation of the Center from the Directors of the Installation Support Activity, the Realignment Implementation Office, and the Safety, Surety and Environmental Offices through the ARDEC Technology Transfer Manager or his designee who, at his discretion, may meet with CCM quarterly for the first year to review the operation of the Technology Innovation Center.

- $\quad$ Provide other support as agreed.

\section{THE COUNTY COLLEGE OF MORRIS WILL:}

- $\quad$ Operate or employ an operator who will manage the entire project.

- $\quad$ Provide temporary space within the Technology Innovation Center to ARDEC CRADA partners at reasonable rates and oversee the use of such space by ELIGIBLE ORGANIZATIONS.

- Manage the Technology Innovation Center to insure safe conditions.

- Further the ARDEC technology transfer mission by assisting potentially ELIGIBLE ORGANIZATIONS in learning about available ARDEC technology and entering into Cooperative Research and Development Agreements with ARDEC.

- $\quad$ Provide a point of contact to familiarize potential ELIGIBLE ORGANIZATIONS with available ARDEC technology, equipment and facilities.

- Develop working relationships with ARDEC technologists and, working with the ARDEC Technology Transfer Manager, develop regular and rapid CRADA formation.

- $\quad$ Provide coordination and a point of contact for interface between Federal, State, and Local providers of management and technical services such as the New Jersey Small Business Investment Council, the New Jersey Small Business Development Centers, the Small Business Administration, and similar public organizations, banks, venture capital and export groups.

- $\quad$ Provide pooled secretarial and administrative assistance and other services to ELIGIBLE ORGANIZATIONS.

- Provide a communal conference room(s) for use of ELIGIBLE ORGANIZATIONS. 
- $\quad$ Provide individual counseling for ELIGIBLE ORGANIZATIONS who which assistance in creating and presenting debt and equity finance packages.

- $\quad$ Pay monthly to ARDEC the Utilization Fee determined pursuant to Article 4 of the Agreement.

- $\quad$ Meet with the ARDEC oversight Board quarterly during the first year to review the operation of the Technology Innovation Center.

- $\quad$ Provide other support as agreed. 


\section{APPENDIX TO CRADA \\ STATEMENT OF WORK \\ TECHNOLOGY INNOVATION CENTER \\ RESOURCES DEDICATED TO THIS CRADA}

\section{ARDEC WILL PROVIDE:}

- Appropriate building or buildings in a condition suitable for the use intended.

- Modular office sections and office furniture and equipment as available.

- $\quad$ Services as agreed.

\section{THE TECHNOLOGY INNOVATION CENTER WILL PROVIDE:}

- The organizational costs of the Center.

- Personnel to manage and operate the Center.

- Dissemination of information about available ARDEC technology

- The operation of the Center. 